\title{
Defining Growth Hormone Status in Adults with Hypopituitarism
}

\author{
K. Kaushal S.M. Shalet \\ Department of Endocrinology, Christie Hospital NHS Trust, Manchester, UK
}

\section{Key Words}

Growth hormone deficiency · Adults, growth hormone deficiency $\cdot$ Hypopituitarism $\cdot$ Transition period •

Assessment, hypopituitarism

\begin{abstract}
The identification of adults with severe growth hormone $(\mathrm{GH})$ deficiency (GHD) is not straightforward. The insulin tolerance test remains the gold standard diagnostic test, although other stimuli such as $\mathrm{GH}$-releasing hormone-arginine are gaining acceptance. Insulin-like growth factor-I has a poor diagnostic sensitivity in adult-onset GHD, but is more useful in the subgroup of adults with childhood-onset GHD. Therapeutic developments include increasing recognition of the need to continue GH therapy beyond final height in young adults with severe GHD on retesting. Consensus guidelines have provided a useful algorithm to identify individuals requiring retesting and the number of tests needed. The concept of partial GHD, recognized by paediatric endocrinologists for many years, is being examined in adults with hypothalamic-pituitary disease. Preliminary evidence suggests that this entity is associated with metabolic and anthropometric abnormalities intermediate between those in severe GHD and in healthy controls. It remains to be seen whether this subgroup will derive benefit from GH therapy. To date, therapeutic benefits of $\mathrm{GH}$ have been demonstrated only in adults with severe GHD. It is, therefore, imperative that these individuals are unequivocally identified; the diag-
\end{abstract}

nosis becomes more uncertain in the presence of obesity, increasing age, and in the absence of additional pituitary hormone deficits.

Copyright $\odot 2007$ S. Karger AG, Basel

\section{Introduction}

For adults proven benefits of recombinant human (rh) growth hormone $(\mathrm{GH})(\mathrm{rhGH})$ replacement therapy have been demonstrated in those with severe GH deficiency (GHD) [1-4]. The diagnosis of GHD in adults remains challenging, since there is no single specific biological end point equivalent to growth failure in children. Current consensus guidelines recommend GH treatment for adults with severe GHD, defined arbitrarily by a GH peak to an insulin tolerance test (ITT) of $<3 \mu \mathrm{g} / \mathrm{l}(9 \mathrm{mU} / \mathrm{l})$ [5]. However, an ITT may be contra-indicated because of ischaemic heart disease or epilepsy, and although there is a wide variety of alternative tests, there remains a lack of normative data to enable test-specific diagnostic cut-off values to be defined. It is also imperative that a single diagnostic threshold for the GH assay is not applied across laboratories, as different assays may be in use. Furthermore, interpretation of test results in specific situations such as obesity and old age remains problematic.

The most common causes of adult-onset GHD (AOGHD) are pituitary and extrapituitary tumours and/or their treatment [6]. In children, GHD is most commonly 
thought to be hypothalamic rather than pituitary in origin, and although multiple causes exist, the commonest diagnosis by far is isolated idiopathic GHD [7]. In contrast to adults, children with all grades of GHD are treated with GH; this has arisen in part due to an increased availability of rhGH. Consensus guidelines from the $\mathrm{GH}$ Research Society (GRS) state that although traditionally a peak GH level on provocative testing of $<10 \mu \mathrm{g} / \mathrm{l}$ supports a diagnosis of GHD in a poorly growing child, this value needs to be revised when using newer assays [8]. A GH peak of between 7 and $10 \mu \mathrm{g} / \mathrm{l}$ is usually taken as the cut-off [9]. As in adults, the cut-off value is arbitrarily defined, since in reality GH secretion is a continuum between normality and abnormality.

\section{Retesting Individuals with Childhood-Onset GHD (CO-GHD) at Final Height (FH)}

Individuals with CO-GHD should have their GH status reassessed after attainment of final height $(\mathrm{FH})$. Currently, continuation of rhGH therapy is indicated only when severe GHD, using adult criteria, is documented on retesting [8]. A significant proportion of individuals treated for GHD during childhood will not meet these criteria $[4,10]$. This may be due to the different criteria for the diagnosis of GHD in children versus adults (all degrees of GHD vs. only severe GHD), poor reproducibility of diagnostic tests [11], misdiagnosis of constitutional delay in growth and puberty as idiopathic GHD, or indeed because a 'transient' state of GHD truly exists in childhood. Guidelines from the GRS recommended that $\mathrm{GH}$ retesting was unnecessary in individuals with severe long-standing multiple pituitary hormone deficits (MPHD), genetic defects, and severe organic GHD [8]. However, a recent study of 73 adolescents with CO-GHD secondary to cranial irradiation [12] found that $48 \%$ of them were not severely GHD on retesting. Of 33 individuals who had been diagnosed with severe GHD at initial testing in childhood, only $64 \%$ were severely GHD on retesting. The authors [12] concluded that retesting at $\mathrm{FH}$ should be performed in all adolescents treated with rhGH for radiation-induced CO-GHD.

Radiology of the hypothalamic-pituitary (H-P) region using magnetic resonance imaging may also be helpful in determining the requirement for retesting at FH. Maghnie et al. [13] found that GHD was permanent in the presence of pituitary hypoplasia, pituitary stalk agenesis, or ectopic posterior pituitary (EPP). These authors felt that retesting was, therefore, not required in these young adults; however, a more recent study [14] highlighted the importance of the precise location of the EPP in determining the risk of permanent GHD. Of 18 individuals with GHD associated with EPP, only $61 \%$ had severe GHD by adult criteria on retesting. Leger et al. [14] demonstrated that location of the EPP at the median eminence rather than along the pituitary stalk, no visible stalk, and MPHD rather than isolated idiopathic GHD were all predictors of severe GHD on retesting and potentially represented the real subgroup, radiologically defined, in whom retesting was unnecessary.

A consensus statement from the ESPE [15] on the management of GHD during the transition period recommended that re-evaluation of GH status at FH should be performed after rhGH has been discontinued for at least 1 month. Furthermore, the authors stated that the criterion used to define adult GHD, namely peak GH $<3 \mu \mathrm{g} / \mathrm{l}$ to an ITT, is too strict for the transition period. It is, therefore, proposed that the peak GH response for defining GH status in adolescents be $5 \mu \mathrm{g} / \mathrm{l}$; differential peak GH thresholds according to the choice of provocative test have not yet been stipulated, despite the known variability of the GH response to different stimuli [15]. It should be noted that whilst the ITT is recommended as first line, suggested alternative stimuli are arginine or glucagon $[5,15]$. Combined administration of GH-releasing hormone (GHRH) and arginine is thought to be a promising alternative in adults, but perhaps is less so during transition $[4,5]$. In isolated CO-GHD, the hypothalamus is believed to be the site of abnormal pathophysiology rather than the pituitary [4]. A normal response to GHRH in combination with either arginine or pyridostigmine may not reliably rule out GHD due to hypothalamic dysfunction, since these tests are exploring the pituitary secretory capacity [16]. However, more recently, Aimaretti et al. [17] evaluated the diagnostic use of the GHRH-arginine test during the transition period. All individuals had received rhGH in childhood, with GHD diagnosed by a peak GH response $<10 \mu \mathrm{g} / \mathrm{l}$ to two provocative tests. Using a cut-off of $9 \mu \mathrm{g} / \mathrm{l}$ on retesting (1st centile limit for this population), $94 \%$ of the individuals with organic hypopituitarism and 52.1\% of those with isolated idiopathic GHD retested as severe GHD. All subjects with severe GHD confirmed after the GHRH-arginine test also had a peak $\mathrm{GH}<3 \mu \mathrm{g} / \mathrm{l}$ after an ITT. The authors concluded that GHRH-arginine was as reliable as an ITT, provided that appropriate cut-off values were used. However, since an ITT was only performed in those who failed the GHRH-arginine test, some individuals with isolated idiopathic GHD and consequently hypo- 
thalamic dysfunction may have had persistent severe GHD which will have been missed due to reliance on the GHRH-arginine test alone [17].

Current recommendations for retesting at $\mathrm{FH}$ suggest that individuals with a high likelihood of GHD with an insulin-like growth factor-I (IGF-I) standard deviation score (SDS) below -2 off rhGH therapy do not need a GH provocation test. Only those with a normal IGF-I SDS or a low likelihood of GHD should have a provocation test. In the 'low-likelihood' group, the diagnosis of persistent severe GHD is only confirmed if both the IGF-I and the provocation test are abnormal [15]. A 'high likelihood' of GHD is defined as severe GHD in childhood, due to a genetic cause, structural $\mathrm{H}-\mathrm{P}$ disease, or central nervous system tumours, or as severe GHD in those who received high-dose cranial irradiation. Attanasio et al. [18] demonstrated that $16.2 \%$ of the individuals with severe COGHD were discordant for the two tests on retesting. The precise $\mathrm{GH}$ status of these individuals is not known.

\section{Assessment of GHD in Adults}

Biochemical testing for GHD should be performed when there is a high probability of H-P disease and clinical features consistent with GHD [5]. Despite the lack of a specific biological end point in $\mathrm{AO}-\mathrm{GHD}$, assessment of $\mathrm{GH}$ status is aided by the known pattern of evolution of anterior pituitary dysfunction in organic H-P disease. GHD is the earliest feature of hypopituitarism [19], and its presence is related to the number of additional pituitary hormone deficits (PHDs). Patients with two or more PHDs have an $87-91 \%$ chance of having severe GHD on an ITT [20-22]. Toogood et al. [20] also demonstrated an increasing severity of GHD, as assessed by a decreasing peak GH response to an ITT, with increasing numbers of additional PHDs [peak $3.8 \mathrm{ng} / \mathrm{ml}$ (isolated GHD), $1.5 \mathrm{ng} /$ $\mathrm{ml}$ (GHD + 1 PHD), $0.8 \mathrm{ng} / \mathrm{ml}$ (GHD + 2 PHDs), and 0.7 $\mathrm{ng} / \mathrm{ml}$ (GHD +3 PHDs)]. This has been confirmed by other investigators [23].

\section{Provocative Tests of GH Secretion in Adults}

The ITT remains the choice for diagnosis of GHD in adults $[5,15]$ and allows concomitant assessment of the pituitary-adrenal axis. A nadir blood glucose level $<2.2$ $\mathrm{mmol} / \mathrm{l}$ is generally regarded as sufficient to provoke $\mathrm{GH}$ secretion. Hoffman et al. [24] found a clear separation of peak GH responses to the ITT between hypopituitary $(<0.2-3.1 \mathrm{ng} / \mathrm{ml})$ and normal middle-aged adults $(5.3-$ $42.5 \mathrm{ng} / \mathrm{ml}$ ). There were no differences in age, sex distri- bution, or body mass index (BMI) between the groups. Using a cut-off value of $5 \mathrm{ng} / \mathrm{ml}$, the ITT was shown to have a $97 \%$ specificity, a $100 \%$ sensitivity, a $99 \%$ positive predictive value, and a $100 \%$ negative predictive value for the diagnosis of GHD in adults [25].

A number of other provocative tests have been evaluated, including arginine, glucagon, clonidine, levodopa, and GHRH, either alone or in combination with other agents. The ITT provides a much more profound stimulus to GH release than glucagon, arginine, or clonidine in young normal males [26]; clonidine was no better than placebo, whilst glucagon proved a more potent stimulus than arginine [26]. Aimaretti et al. [27] found that the peak GH response to an ITT was similar to that of arginine and glucagon in a cohort of normal adults, with the response to clonidine being much lower. Their study differed from that of Rahim et al. [26], in that not all adults underwent all tests, and secondly, the study cohort consisted of both males and females. Although there was no gender difference in the GH response to the ITT, glucagon, or clonidine, women had a significantly higher peak response to arginine, thought to be due to an enhancing effect of oestrogens [27]. The arginine stimulation test has been shown to have a significantly lower specificity than the ITT [28].

Although the ITT is regarded as the gold standard, its disadvantages are that it is unpopular with patients [22], and there are several contra-indications to its use. Adequate supervision is essential during the test, and it should only be performed in experienced endocrine units. The ITT has also been shown to have poor intra-individual reproducibility on repeated testing in healthy individuals $[29,30]$. In several of the normal women investigated by Hoeck et al. [29], at least one of two ITTs produced a peak $\mathrm{GH}<5 \mu \mathrm{g} / \mathrm{l}$, illustrating that a single provocative test may be inadequate to exclude GHD, particularly in women. The intra-individual variability of the $\mathrm{GH}$ response to the ITT is much lower in hypopituitary as compared with normal men [31]. As with the study of Hoeck et al. [29], testing in men correctly classified normal subjects as being $\mathrm{GH}$ replete, with an overall range of peak $\mathrm{GH}$ values across all three ITTs performed of 70-273.5 mU/1 [31]. Poor reproducibility is also a problem with other provocative tests of $\mathrm{GH}$ secretion [32].

Like the ITT, GHRH plus arginine distinguishes between normal and hypopituitary adults of all ages and appears superior to the GHRH-pyridostigmine test which only provides a clear differentiation between the ages of 20 and 40 [33]. In this study, there was a range of 16.1$119.0 \mu \mathrm{g} / \mathrm{l}$ for GHRH-arginine in normal subjects, with 
the highest value in the hypopituitary group being 9.5 $\mu \mathrm{g} / \mathrm{l}$. Arginine and pyridostigmine potentiate GHRH activity by inhibiting somatostatin release. The ITT and GHRH-arginine produce the best separation between subjects with MPHD and controls as compared with arginine, levodopa, and arginine plus levodopa in subjects matched for age, sex, BMI, and oestrogen status [22]. GHRH-arginine appears to have a good intra- and interindividual reproducibility [34] and produces a much greater peak GH response than an ITT $[22,27,35]$. Aimaretti et al. [27] defined first- and third-centile normative limits for the peak GH response to the various stimuli investigated in normal adults, in order to establish test cut-off values for the diagnosis of severe GHD. The firstcentile limit for GHRH-arginine was $15.2 \mu \mathrm{g} / \mathrm{l}$, and for the ITT it was $3.8 \mu \mathrm{g} / \mathrm{l}$ which is very close to the $3 \mu \mathrm{g} / \mathrm{l}$ threshold recommended by the GRS [5]. For arginine, the threshold was $2.7 \mu \mathrm{g} / \mathrm{l}$ and for glucagon, rather surprisingly, $7.1 \mu \mathrm{g} / \mathrm{l}$ [27]. A diagnostic cut-off value of $9 \mu \mathrm{g} / \mathrm{l}$ for GHRH-arginine has been used in our unit [35] and by others [36], as previously suggested by Aimaretti et al. [37]. Biller et al. [22], however, found that a lower cut-off of $4.1 \mu \mathrm{g} / \mathrm{l}$ using GHRH-arginine produced the best sensitivity (95\%) and specificity (91\%) for the diagnosis of GHD as compared with a sensitivity of $96 \%$ and a specificity of $92 \%$ using a cut-off of $5.1 \mu \mathrm{g} / \mathrm{l}$ to an ITT [22]. This suggests that GHRH-arginine can be as sensitive as the ITT, provided appropriate cut-off values are used, and a lower cut-off can maximize the diagnostic specificity.

GHRH-arginine and GHRH-pyridostigmine tests should only be used where there is reasonable certainty that the patient has pituitary rather than hypothalamic disease. Whilst the pituitary is believed to be the main site of involvement in the majority of individuals with $\mathrm{AO}-\mathrm{GHD}$, hypothalamic involvement is more likely in those whose GHD is secondary to cranial irradiation [35, 38]. Although hypothalamic dysfunction is an early effect after irradiation, somatotroph function declines gradually with time. The combined GHRH-arginine test may, therefore, fail to diagnose GHD, particularly if performed in the first 5 years after irradiation [35]. In fact, the risk of misclassification of GH status may persist for as long as 10-15 years. However, over time, the discordance between the ITT (showing a reduced response) and GHRH-arginine test (showing a preserved response) diminishes. The poor sensitivity of the combined test in the early years after cranial irradiation has recently been confirmed in a study of young adults [36].

Another diagnostic test for GHD which has been well validated is the combination of GHRH and GH-releasing peptide-6 (GHRP-6) $[6,39]$. GHRP-6 is a synthetic hexapeptide which is thought to activate both a hypothalamic and a pituitary receptor [40]. In a study of 125 individuals with organic H-P disease with confirmed severe GHD (GH peak after ITT $\leq 3 \mu \mathrm{g} / \mathrm{l})$ and 125 age-matched controls, this test had $100 \%$ sensitivity, based on a peak GH threshold of $20 \mu \mathrm{g} / \mathrm{l}$, and $100 \%$ specificity, based on a threshold of $10 \mu \mathrm{g} / \mathrm{l}$ [39]. The two thresholds were suggested since complete separation of patients and controls did not occur, $12 \%$ of cases having values between 10 and $20 \mu \mathrm{g} / \mathrm{l}$. As with the combined GHRH-arginine test, this test may be best limited to those with pituitary disease, since the GH response may be preserved in patients with hypothalamic dysfunction [41]. Popovic et al. [39] suggested that for patients with a peak GH response of between 10 and $20 \mu \mathrm{g} / \mathrm{l}$, further stimulatory testing and evaluation of clinical information may be necessary, as the GH status was uncertain.

\section{Role of IGF-I in the Assessment of GHD in Adults}

It is now widely accepted that circulating IGF-I concentrations do not reliably distinguish between GH-deficient and normal adults in all age groups $[4,22,24,33$, 42-44]. Serum IGF-I concentrations must be interpreted using age-adjusted normal ranges, since adult levels decline with increasing age [45]. In adults with severe GHD between 20 and 40 years of age, the overlap of IGF-I concentrations with normal subjects is much lower $(8.6 \%)$ as compared with those aged $41-60$ years (50\%) and 61-80 years $(92.3 \%)$ [33]. Therefore, IGF-I is a very useful diagnostic marker for GHD in adults $<40$ years of age $[33,42]$. A multicentre study of patients with AO-H-P disease and MPHDs $(\geq 2)$, who were, therefore, assumed to have GHD, found that an IGF-I cut-off of $77.2 \mu \mathrm{g} / \mathrm{l}$ had a $95 \%$ specificity for the diagnosis of GHD, with a sensitivity of $40 \%$ [22]. An IGF-I SDS cut-off of -2 in the same study yielded a specificity of $100 \%$ and a sensitivity of $46 \%$. Thus, a subnormal IGF-I is highly suggestive of GHD in adults, but a normal level does not exclude the diagnosis. Naturally the cut-off level given in this study was specific to this particular laboratory and cannot be extrapolated to other centres. Although IGF-I SDS values in individuals with AO-GHD frequently overlap with those of normal subjects, this overlap has been shown to be limited mainly to the lower half of the age-related IGF-I reference range (fig. 1) [46].

It has now become clear that the timing of onset of GHD influences the circulating IGF-I level [47]. In cohorts of adults with severe GHD, IGF-I levels are significantly lower in $\mathrm{CO}$ versus AO disease; Hilding et al. [43] 

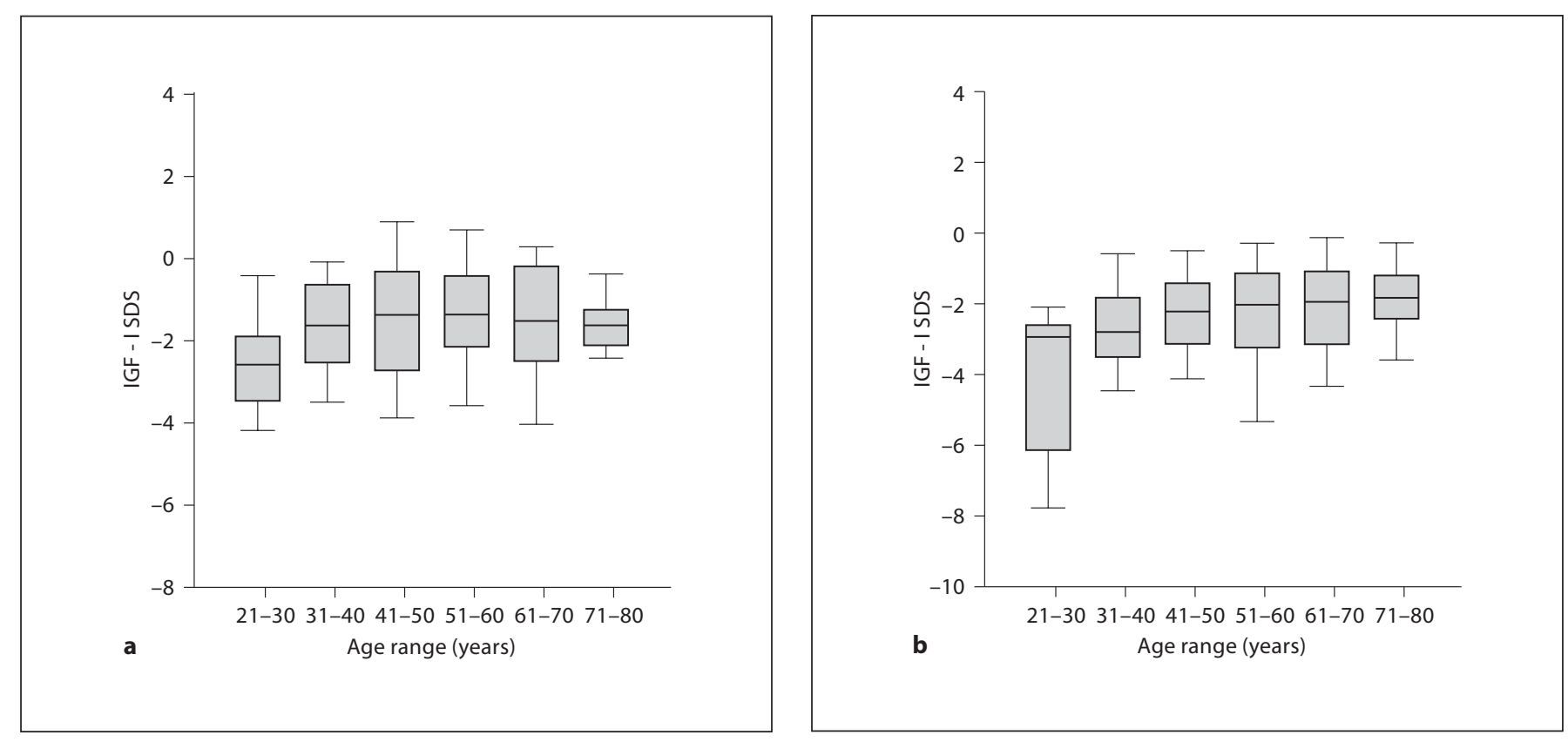

Fig. 1. Box-and-whisker plots representing IGF-I SDS values for six age ranges in males (a) and females (b) having severe AO-GHD. The lower boundary of the box indicates the 25 th percentile, a line within the box marks the median, and the upper boundary of the box indicates the 75th percentile. Error bars above and below the box indicate the 90th and 10th percentiles, respectively. The figure demonstrates that overlap of IGF-I SDS values between GHD and normal adults is predominantly limited to the lower half of the normal age-related reference range. [From ref. 46, with permission, copyright 2003, The Endocrine Society]

found that $34 \%$ of the individuals with AO-GHD had IGF-I values within the normal range, whilst in adults with CO-GHD, all IGF-I values fell below -2 SDS. The lower level in CO-GHD is not due to increased severity of disease [47]. Lissett et al. [47] compared IGF-I levels in adults with CO-GHD $(n=63)$ and AO-GHD $(n=83)$. All patients were subdivided by severity of GHD, as measured by the peak GH response to an ITT ( $\leq 1 \mathrm{mU} / \mathrm{l},>1-$ $3 \mathrm{mU} / \mathrm{l}, 3-6 \mathrm{mU} / \mathrm{l}$, and $>6-8.9 \mathrm{mU} / \mathrm{l})$. In the first three subgroups (more severe), the IGF-I SDS values were significantly lower for CO-GHD versus AO-GHD, despite the fact that there was no difference in mean peak $\mathrm{GH}$ response to the ITT for CO-GHD and AO-GHD patients within each group. The authors have hypothesized about the reasons for this innate difference in circulating IGF-I concentrations between $\mathrm{CO}-\mathrm{GHD}$ and $\mathrm{AO}-\mathrm{GHD}$. Either the onset of GHD early in life somehow alters the IGF-I responsiveness to $\mathrm{GH}$, or AO-GHD patients, who have a higher BMI than CO-GHD patients, have higher insulin levels, known to stimulate IGF-I production. In a larger study of 1,317 adults with GHD, multiple regression analysis confirmed that the age at onset of GHD was the most important determinant of IGF-I SDS values [48]. Prolactin deficiency may also contribute to the variation in adult IGF-I levels [49]; multiple regression analysis showed that CO-GHD and prolactin deficiency were independently associated with a reduced IGF-I status. Gender, BMI, and number of additional PHDs had no independent association with IGF-I. GH and prolactin share structural homology and common signaling intermediates; it can be hypothesized that in prolactin-replete individuals, in the absence of $\mathrm{GH}$, prolactin stimulates IGF-I production. Alternatively, prolactin deficiency may purely be a surrogate for the severity of GHD [49].

\section{Other Biochemical Tests Used to Diagnose GHD in Adults}

The use of serum insulin-like growth factor binding protein-3 measurement, 24-hour GH profiles, and urinary GH measurement has been reviewed previously [4]. In practice, insulin-like growth factor binding protein-3 has contributed nothing diagnostically to the investigation of GH status in the adult patient due to the marked overlap with the range of values seen in normal subjects. 
Twenty-four-hour GH profiles are a true measure of spontaneous GH secretion, but are labour-intensive and costly, requiring blood samples to be taken at least every $20 \mathrm{~min}$. The mean integrated 24-hour GH concentration does not reliably separate GHD from normal adults [24, 50]. Its main use is, therefore, as a research tool in the study of GHD. There has been considerable interest in urinary GH measurement over the years, largely due to the non-invasive nature of this test. However, it has not been found to be a reliable diagnostic marker of GHD, particularly in older patients $[4,21,51,52]$.

\section{How Many Stimulation Tests Are Required for the Diagnosis of GHD?}

In adults with two or three additional PHDs, in whom the likelihood of GHD being present is extremely high, only one provocative test of GH secretion is required for the diagnosis of severe GHD $[4,53]$. Those with only one or no additional PHD require two provocative tests, since the chance of misclassification of GH status by a single test is high in these individuals [53].

A more recent study [23] has shown that in adults with severe GHD, as measured by a response to a GH stimulation test of $<2.5 \mu \mathrm{g} / \mathrm{l}$, the presence of either three or more additional PHDs (gonadotrophins, adrenocortcotrophic hormone, thyroid-stimulating hormone, and arginine vasopressin) or a serum IGF-I concentration $<84 \mu \mathrm{g} / \mathrm{l}$ has a $95 \%$ positive predictive value for GHD, the specificity being $89 \%$ and the sensitivity $69 \%$. The authors recommend that individuals fulfilling either of these criteria do not require stimulation testing for the diagnosis of GHD. However, it should be noted that this particular IGF-I cutoff applies only to the assay used in the study. Furthermore, eleven different stimulation tests were used, only $11.4 \%$ of patients undergoing an ITT. To compensate for this, the authors used a stricter GH threshold of $2.5 \mu \mathrm{g} / \mathrm{l}$.

\section{Difficulties with the Diagnosis of GHD in Obese}

Individuals

Obesity is associated with reduced GH concentrations, due to a combination of decreased GH production and increased clearance [54]. GH secretion may be normalized by weight loss [55]. Furthermore, adults with GHD have increased body fat, particularly central abdominal fat, and are insulin resistant [6]. This makes the distinction between individuals with simple obesity and those with organic GHD extremely difficult.

Obese men produce $75 \%$ less $\mathrm{GH}$ over a 24 -hour period as compared with age-matched non-obese controls [54]. The results of GH provocative testing need to be in- terpreted with caution in those with even modest elevations of BMI [4]. Bonert et al. [56] examined the peak GH following GHRH-arginine in healthy males and found a subnormal response in $13 \%$ with a BMI $25-26.9$, in $33 \%$ with a BMI $27-29.9$, and in $64 \%$ with a BMI $\geq 30$. Abdominal visceral fat, rather than total fat mass or percentage body fat, appears to be the major determinant of 24hour integrated GH concentration, independently of age and gender [57]. This may be due to negative feedback at the H-P axis by insulin and free fatty acids from the increased abdominal visceral fat. The contribution of visceral adiposity in determining GH levels was recently confirmed by Miller et al. [58]. The authors studied 15 healthy women with a normal BMI and found that GH levels were significantly lower in the subgroup with high versus low truncal fat.

\section{Difficulties with the Diagnosis of GHD in the Elderly}

There is a decrease in GH secretion with increasing age, causing potential difficulties in discriminating between healthy and GHD elderly adults. In one study [57], older subjects (aged 57-80 years) had an approximately $50 \%$ lower 24 -hour integrated GH concentration as compared with younger adults (aged $20-29$ years). Spontaneous GH secretion falls by $14 \%$ per decade of adult life [59]. Normal ageing is associated with body composition changes similar to those evident in GHD $[4,60]$. Old age can be considered a state of functional GH insufficiency (GHI). However, to date, there is no conclusive evidence that rhGH offers any significant long-term therapeutic benefit in the hyposomatotropism of ageing, and the risk of adverse events is high [61].

Identification of GHD in elderly individuals with H-P disease is important, since they do have changes in body composition, abnormal lipid profiles, and impairment of quality of life similar to those in younger adults [62], and many of these clinical characteristics improve with rhGH therapy $[60,62,63]$. The presence of GHD in these older individuals ( $>60$ years) causes a greater reduction in $\mathrm{GH}$ secretion than that which occurs simply with ageing [51, 64]. In the study of Toogood et al. [64], GH secretion in GHD subjects $>60$ years, measured by median area under the curve of the 24 -hour GH profile, was only $12 \%$ of that in healthy age-, gender-, and BMI-matched controls. The peak GH concentrations, although significantly lower in patients than in controls, still overlapped between the two groups. The ITT is best avoided in adults $>60$ years old, due to a potential increase in morbidity and mortality [4], and suitable alternatives may be the GHRH-arginine test, which showed complete separation between 
GHD and healthy elderly individuals [34], the arginine stimulation test, provided at least two additional PHDs are present [65], and potentially the GHRH-GHRP-6 test which is unaffected by age [39]. Like GH, IGF-I levels decrease with age and are unhelpful in the diagnosis of GHD in elderly subjects, due to significant overlap between GHD patients and healthy controls $[33,51,65]$.

\section{Partial GHD in Adults}

The concept of 'partial' deficiency is widely accepted in endocrinology for hormones such as arginine vasopressin, gonadotrophins, adrenocorticotrophic hormone, or thyroid-stimulating hormone. Similarly, GH secretion occurs across a continuum between normality and abnormality, and it is, therefore, logical to assume that a state of partial GHD (GHI) exists in adults with H-P disease. Further support for this diagnosis in adults is provided by the fact that GHI in childhood has been recognized for many years. Since severe GHD is defined by an arbitrary cut-off of $3 \mu \mathrm{g} / \mathrm{l}$ on an ITT, and most normal adults have a peak $\mathrm{GH}$ response $>7 \mu \mathrm{g} / \mathrm{l}, \mathrm{GHI}$ is defined by an intermediate response of 3-7 $\mu \mathrm{g} / \mathrm{l}$. Using the $\mathrm{GHRH}$-arginine test, $\mathrm{GHI}$ is defined by a peak response of between 9 and $21 \mu \mathrm{g} / 1$ [66].

Recently, it has become clear that adolescents with evidence of GHI on retesting at FH exhibit an abnormal body composition as compared with those retesting normal [67]. Furthermore, these characteristics deteriorate after 1 year off rhGH in the GHI subgroup, remaining unchanged in normals [67]. It has now been demonstrated that partial GHD in adults is associated with changes in body composition (reduced lean body mass and increased percent fat mass, waist-to-hip ratio, and skinfold thickness) [66] and lipid abnormalities (elevated total and low-density lipoprotein cholesterol) [68], intermediate between those seen in GHD adults and healthy controls. Patients with GHI, whether of childhood or adult onset, have no significant impairment of bone mineral density $[69,70]$.

Individuals with GHD and GHI have similar degrees of insulin resistance, compared with age-, sex-, and BMImatched controls [71]. In this study, although the subjects were matched for BMI, total body fat and truncal fat mass were greater in the two patient groups as compared with the controls. Indeed, increased abdominal fat (indicative of visceral adiposity) is thought to be the major determinant of insulin resistance, rather than the BMI [72]. It is, therefore, highly probable that patients with GHI, like those with GHD, are at increased risk of premature vas-
Table 1. Key summary points

- Benefits of rhGH therapy have been demonstrated only in adults with severe GHD, defined as a GH peak to an ITT of $<3 \mu \mathrm{g} / 1$

- For the diagnosis of severe GHD in adolescents at FH, the ESPE guidelines recommend a GH cutoff of $5 \mu \mathrm{g} / \mathrm{l}$ to any provocative test

- The ESPE guidelines recommend that provocative retesting of the GH status at FH is unnecessary in those with a high likelihood of severe GHD and an IGF-I SDS below -2

- GHRH combined with either arginine or GHRP-6 may be useful alternatives to the ITT for the diagnosis of severe GHD of pituitary rather than hypothalamic origin

- Serum IGF-I has poor diagnostic sensitivity in AO-GHD, but can be very helpful in adults with CO-GHD

- An individual is more likely to have severe GHD in the presence of MPHDs

- The diagnosis of severe GHD can be extremely difficult in obese or older individuals, especially in the absence of additional PHD

- Partial GHD is associated with metabolic and anthropometric abnormalities intermediate between severe GHD and healthy controls, but the benefits of rhGH therapy in this condition remain uncertain

- For accurate diagnosis of GHD, each laboratory must define stimulus-specific reference ranges

cular disease, due to the presence of features of the metabolic syndrome.

Although these group studies have indicated changes in biological end points in GHI, the difficulty of making this diagnosis in an individual patient is considerable. Visceral obesity is associated with reduced serum GH concentrations, and there is, therefore, an inherent risk of misdiagnosing GHI in obese but otherwise 'normal' subjects. Moreover, the majority of GHI individuals have no additional anterior PHDs and a normal IGF-I value, making it even more difficult to establish with any certainty that a patient with a putative insult to the H-P axis has impaired GH status [73]. Furthermore, the question of whether an individual demonstrated to have GHI would benefit from rhGH replacement remains unproven. Improvements in body composition with rhGH could not be regarded as offering any diagnostic implications, as similar changes would be anticipated in those with normal $\mathrm{GH}$ status. At the very least, patients in whom the diagnosis of GHI is suspected require prolonged follow-up. The key summary points are also shown in table 1. 


\section{Conclusions}

The ideal test for diagnosing severe GHD is one which distinguishes between health and disease on an individual basis, has good reproducibility and tolerability, is not significantly affected by age, gender or adiposity, and is relatively simple to perform. The potency of the stimulus during a provocative test is also critical, so that there should be a pronounced GH response in normals, with few individual failures. Serum measurement of IGF-I is helpful in CO-GHD; however, in AO-GHD, a normal age- and sex-adjusted IGF-I level does not exclude the diagnosis of severe GHD, although a low result is useful for screening.

The ITT has suffered much criticism over recent years, but there is considerable experience in its use; the stimulus (insulin) is available in every endocrine unit, it enables simultaneous assessment of adrenocorticotrophic hormone secretion, and it is still the diagnostic test recommended as first-line procedure by the GRS [5]. GHRH in combination with arginine or GHRP- 6 provides a more reproducible, potent alternative to the ITT in AO-GHD. However, these tests have not yet been widely used across the endocrine community, and moreover GHRP- 6 is not easily available. The GRS advocates international standardization of GH assays [5]. Furthermore, it is imperative that each endocrine laboratory defines its own stimulus-specific reference ranges by studying the local population, rather than simply adopting diagnostic cut-off values used in other centres.

Defining GHD clinically in adults with hypopituitarism is not always straightforward, particularly since phenotypic features of the adult GHD syndrome are nonspecific. It is only in adults with severe GHD that the benefits of rhGH therapy have been demonstrated, and these individuals, therefore, need to be identified. In general, the younger and slimmer the patient, plus the presence of multiple additional PHD, the more severe the GHD and the more certain the diagnosis. In contrast, in older or more obese patients, with no additional PHD, the less severe is the GHD and the more difficult the diagnosis.

\section{References}

1 Jorgensen JO, Pedersen SA, Thuesen L, Jorgensen J, Ingemann-Hansen T, Skakkebaek NE, Christiansen JS: Beneficial effects of growth hormone treatment in GH-deficient adults. Lancet 1989;1:1221-1225.

-2 Salomon F, Cuneo RC, Hesp R, Sonksen PH: The effects of treatment with recombinant human growth hormone on body composition and metabolism in adults with growth hormone deficiency. N Engl J Med 1989;321: 1797-1803.

-3 Bengtsson BA, Eden S, Lonn L, Kvist H, Stokland A, Lindstedt G, Bosaeus I, Tolli J, Sjöstrom L, Isaksson OG: Treatment of adults with growth hormone (GH) deficiency with recombinant human GH. J Clin Endocrinol Metab 1993;76:309-317.

-4 Shalet SM, Toogood A, Rahim A, Brennan BM: The diagnosis of growth hormone deficiency in children and adults. Endocr Rev $1998 ; 19: 203-223$.

5 Consensus guidelines for the diagnosis and treatment of adults with growth hormone deficiency: summary statement of the Growth Hormone Research Society Workshop on Adult Growth Hormone Deficiency. J Clin Endocrinol Metab 1998;83:379-381.

6 Ho KY: Growth hormone deficiency in adults; in DeGroot LJ, Jameson JL (eds): Endocrinology. Philadelphia, Elsevier, 2006, pp 755-765.
7 Dattani MT, Hindmarsh PC: Growth hormone deficiency in children; in DeGroot LJ, Jameson JL (eds): Endocrinology. Philadelphia, Elsevier, 2006, pp 733-754.

$\checkmark 8$ Consensus guidelines for the diagnosis and treatment of growth hormone $(\mathrm{GH})$ deficiency in childhood and adolescence: summary statement of the GH Research Society. GH Research Society. J Clin Endocrinol Metab 2000;85:3990-3993.

-9 Drake WM, Howell SJ, Monson JP, Shalet SM: Optimizing GH therapy in adults and children. Endocr Rev 2001;22:425-450.

10 Stavrou S, Kleinberg DL: Diagnosis and management of growth hormone deficiency in adults. Endocrinol Metab Clin North Am 2001;30:545-563.

11 Van den Broeck J, Hering P, Van de Lely A, Hokken-Koelega A: Interpretative difficulties with growth hormone provocative retesting in childhood-onset growth hormone deficiency. Horm Res 1999;51:1-9.

12 Gleeson HK, Gattamaneni HR, Smethurst L, Brennan BM, Shalet SM: Reassessment of growth hormone status is required at final height in children treated with growth hormone replacement after radiation therapy. J Clin Endocrinol Metab 2004;89:662-666.
13 Maghnie M, Strigazzi C, Tinelli C, Autelli M, Cisternino M, Loche S, Severi F: Growth hormone (GH) deficiency (GHD) of childhood onset: reassessment of GH status and evaluation of the predictive criteria for permanent GHD in young adults. J Clin Endocrinol Metab 1999;84:1324-1328.

14 Leger J, Danner S, Simon D, Garel C, Czernichow P: Do all patients with childhoodonset growth hormone deficiency (GHD) and ectopic neurohypophysis have persistent GHD in adulthood? J Clin Endocrinol Metab 2005;90:650-656.

15 Clayton PE, Cuneo RC, Juul A, Monson JP, Shalet SM, Tauber M; European Society of Paediatric Endocrinology: Consensus statement on the management of the GH-treated adolescent in the transition to adult care. Eur J Endocrinol 2005;152:165-170.

16 Ghigo E, Bellone J, Aimaretti G, Bellone S, Loche S, Cappa M, Bartolotta E, Dammacco F, Camanni F: Reliability of provocative tests to assess growth hormone secretory status. Study in 472 normally growing children. J Clin Endocrinol Metab 1996;81:3323-3327.

-17 Aimaretti G, Baffoni C, Bellone S, Di Vito L, Corneli G, Arvat E, Benso L, Camanni F, Ghigo E: Retesting young adults with childhood-onset growth hormone (GH) deficiency with GH-releasing-hormone-plus-arginine test. J Clin Endocrinol Metab 2000;85: 3693-3699. 
18 Attanasio AF, Howell S, Bates PC, Blum WF, 31 Pfeifer M, Kanc K, Verhovec R, Kocijancic A: Frewer P, Quigley C, Shalet SM: Confirmation of severe GH deficiency after final height in patients diagnosed as $\mathrm{GH}$ deficient during childhood. Clin Endocrinol (Oxf) 2002;56:503-507.

19 Littley MD, Shalet SM, Beardwell CG, Ahmed SR, Applegate G, Sutton ML: Hypopituitarism following external radiotherapy for pituitary tumours in adults. Q J Med 1989;70:145-160.

20 Toogood AA, Beardwell CG, Shalet SM: The severity of growth hormone deficiency in adults with pituitary disease is related to the degree of hypopituitarism. Clin Endocrinol (Oxf) 1994;41:511-516.

21 Bates AS, Evans AJ, Jones P, Clayton RN: Assessment of GH status in adults with GH deficiency using serum growth hormone, serum insulin-like growth factor-I and urinary growth hormone excretion. Clin Endocrinol (Oxf) 1995;42:425-430.

-22 Biller BM, Samuels MH, Zagar A, Cook DM, Arafah BM, Bonert V, Stavrou S, Kleinberg DL, Chipman JJ, Hartman ML: Sensitivity and specificity of six tests for the diagnosis of adult GH deficiency. J Clin Endocrinol Metab 2002;87:2067-2079.

-23 Hartman ML, Crowe BJ, Biller BM, Ho KK, Clemmons DR, Chipman JJ: Which patients do not require a $\mathrm{GH}$ stimulation test for the diagnosis of adult GH deficiency? J Clin Endocrinol Metab 2002;87:477-485.

-24 Hoffman DM, O'Sullivan AJ, Baxter RC, Ho KK: Diagnosis of growth hormone deficiency in adults. Lancet 1994;343:1064-1068.

25 Hoffman DM, Ho KK: Diagnosis of GH deficiency in adults; in Juul A, Jorgensen JO (eds): Growth Hormone in Adults. Cambridge, Cambridge University Press, 1996, pp 168-185.

26 Rahim A, Toogood AA, Shalet SM: The assessment of growth hormone status in normal young adult males using a variety of provocative agents. Clin Endocrinol (Oxf) 1996; 45:557-562.

-27 Aimaretti G, Baffoni C, DiVito L, Bellone S, Grottoli S, Maccario M, Arvat E, Camanni F, Ghigo E: Comparisons among old and new provocative tests of GH secretion in 178 normal adults. Eur J Endocrinol 2000;142:347352.

28 Fisker S, Jorgensen JO, Orskov H, Christiansen JS: L-Arginine and insulin tolerance tests in the diagnosis of adult growth hormone deficiency: influence of confounding factors. Clin Endocrinol (Oxf) 1998;48:109-115.

- 29 Hoeck HC, Vestergaard P, Jakobsen PE, Laurberg P: Test of growth hormone secretion in adults: poor reproducibility of the insulin tolerance test. Eur J Endocrinol 1995; 133:305-312.

-30 Vestergaard P, Hoeck HC, Jakobsen PE, Laurberg P: Reproducibility of growth hormone and cortisol responses to the insulin tolerance test and the short ACTH test in normal adults. Horm Metab Res 1997;29:106-110. Reproducibility of the insulin tolerance test (ITT) for assessment of growth hormone and cortisol secretion in normal and hypopituitary adult men. Clin Endocrinol (Oxf) 2001; 54:17-22.

32 Hoeck HC, Jakobsen PE, Vestergaard P, Falhof J, Laurberg P: Differences in reproducibility and peak growth hormone responses to repeated testing with various stimulators in healthy adults. Growth Horm IGF Res 1999;9:18-24.

33 Ghigo E, Aimaretti G, Gianotti L, Bellone J, Arvat E, Camanni F: New approach to the diagnosis of growth hormone deficiency in adults. Eur J Endocrinol 1996;134:352-356.

34 Valetto MR, Bellone J, Baffoni C, Savio P, Aimaretti G, Gianotti L, Arvat E, Camanni F, Ghigo E: Reproducibility of the growth hormone response to stimulation with growth hormone-releasing hormone plus arginine during lifespan. Eur J Endocrinol 1996;135:568-572.

35 Darzy KH, Aimaretti G, Wieringa G, Gattamaneni HR, Ghigo E, Shalet SM: The usefulness of the combined growth hormone $(\mathrm{GH})$ releasing hormone and arginine stimulation test in the diagnosis of radiation-induced $\mathrm{GH}$ deficiency is dependent on the post-irradiation time interval. J Clin Endocrinol Metab 2003;88:95-102.

- 36 Ham JN, Ginsberg JP, Hendell CD, Moshang T Jr.: Growth hormone releasing hormone plus arginine stimulation testing in young adults treated in childhood with cranio-spinal radiation therapy. Clin Endocrinol (Oxf) 2005;62:628-632.

37 Aimaretti G, Corneli G, Razzore P, Bellone S, Baffoni C, Arvat E, Camanni F, Ghigo E: Comparison between insulin-induced hypoglycemia and growth hormone (GH)-releasing hormone + arginine as provocative tests for the diagnosis of GH deficiency in adults. J Clin Endocrinol Metab 1998;83:16151618.

38 Blacklay A, Grossman A, Ross RJ, Savage MO, Davies PS, Plowman PN, Coy DH, Besser GM: Cranial irradiation for cerebral and nasopharyngeal tumours in children: evidence for the production of a hypothalamic defect in growth hormone release. J Endocrinol 1986;108:25-29.

39 Popovic V, Leal A, Micic D, Koppeschaar HP Torres E, Paramo C, Obradovic S, Dieguez C, Casanueva FF: GH-releasing hormone and GH-releasing peptide- 6 for diagnostic testing in GH-deficient adults. Lancet 2000;356: $1137-1142$.

40 Casanueva FF, Dieguez C: Growth hormone secretagogues: physiological role and clinical utility. Trends Endocrinol Metab 1999; 10:30-38.

41 Ho KK: Diagnosis of adult GH deficiency. Lancet 2000;356:1125-1126.
42 Aimaretti G, Corneli G, Razzore P, Bellone S, Baffoni C, Bellone J, Camanni F, Ghigo E: Usefulness of IGF-I assay for the diagnosis of GH deficiency in adults. J Endocrinol Invest 1998;21:506-511.

43 Hilding A, Hall K, Wivall-Helleryd IL, Saaf M, Melin AL, Thoren M: Serum levels of insulin-like growth factor I in 152 patients with growth hormone deficiency, aged 1982 years, in relation to those in healthy subjects. J Clin Endocrinol Metab 1999;84: 2013-2019.

44 Marzullo P, Di Somma C, Pratt KL, Khosravi J, Diamandis A, Lombardi G, Colao A, Rosenfeld RG: Usefulness of different biochemical markers of the insulin-like growth factor (IGF) family in diagnosing growth hormone excess and deficiency in adults. J Clin Endocrinol Metab 2001;86:3001-3008.

-45 Juul A, Bang P, Hertel NT, Main K, Dalgaard P, Jorgensen K, Muller J, Hall K, Skakkebaek NE: Serum insulin-like growth factor-I in 1030 healthy children, adolescents, and adults: relation to age, sex, stage of puberty, testicular size, and body mass index. J Clin Endocrinol Metab 1994;78:744-752.

46 Mukherjee A, Monson JP, Jonsson PJ, Trainer PJ, Shalet SM: Seeking the optimal target range for insulin-like growth factor I during the treatment of adult growth hormone disorders. J Clin Endocrinol Metab 2003;88: 5865-5870.

47 Lissett CA, Murray RD, Shalet SM: Timing of onset of growth hormone deficiency is a major influence on insulin-like growth factor I status in adult life. Clin Endocrinol (Oxf) 2002;57:35-40.

48 Lissett CA, Jonsson P, Monson JP, Shalet SM: Determinants of IGF-I status in a large cohort of growth hormone-deficient (GHD) subjects: the role of timing of onset of GHD. Clin Endocrinol (Oxf) 2003;59:773-778.

49 Mukherjee A, Ryder WD, Jostel A, Shalet SM: Prolactin deficiency is independently associated with reduced IGF-I status in severely GHD adults. J Clin Endocrinol Metab 2006;91:2520-2525.

50 Reutens AT, Hoffman DM, Leung KC, Ho KK: Evaluation and application of a highly sensitive assay for serum growth hormone (GH) in the study of adult GH deficiency. J Clin Endocrinol Metab 1995;80:480-485.

51 Gill MS, Toogood AA, O’Neill PA, Thorner MO, Shalet SM, Clayton PE: Urinary growth hormone $(\mathrm{GH})$, insulin-like growth factor I (IGF-I), and IGF-binding protein-3 measurements in the diagnosis of adult GH deficiency. J Clin Endocrinol Metab 1998;83: 2562-2565.

-52 Granada ML, Murillo J, Lucas A, Salinas I, Llopis MA, Castells I, Foz M, Sanmarti A: Diagnostic efficiency of serum IGF-I, IGFbinding protein-3 (IGFBP-3), IGF-I/IGFBP3 molar ratio and urinary $\mathrm{GH}$ measurements in the diagnosis of adult GH deficiency: importance of an appropriate reference population. Eur J Endocrinol 2000;142:243-253. 
53 Lissett CA, Thompson EG, Rahim A, Brennan BM, Shalet SM: How many tests are required to diagnose growth hormone $(\mathrm{GH})$ deficiency in adults? Clin Endocrinol (Oxf) 1999;51:551-557.

54 Veldhuis JD, Iranmanesh A, Ho KK, Waters MJ, Johnson ML, Lizarralde G: Dual defects in pulsatile growth hormone secretion and clearance subserve the hyposomatotropism of obesity in man. J Clin Endocrinol Metab 1991;72:51-59.

-55 Williams T, Berelowitz M, Joffe SN, Thorner MO, Rivier J, Vale W, Frohman LA: Impaired growth hormone responses to growth hormone-releasing factor in obesity. A pituitary defect reversed with weight reduction. N Engl J Med 1984;311:1403-1407.

-56 Bonert VS, Elashoff JD, Barnett P, Melmed S: Body mass index determines evoked growth hormone $(\mathrm{GH})$ responsiveness in normal healthy male subjects: diagnostic caveat for adult GH deficiency. J Clin Endocrinol Metab 2004;89:3397-3401.

57 Clasey JL, Weltman A, Patrie J, Weltman JY, Pezzoli S, Bouchard C, Thorner MO, Hartman ML: Abdominal visceral fat and fasting insulin are important predictors of 24-hour $\mathrm{GH}$ release independent of age, gender, and other physiological factors. J Clin Endocrinol Metab 2001;86:3845-3852.

58 Miller KK, Biller BM, Lipman JG, Bradwin G, Rifai N, Klibanski A: Truncal adiposity, relative growth hormone deficiency, and cardiovascular risk. J Clin Endocrinol Metab 2005;90:768-774.

59 Iranmanesh A, Lizarralde G, Veldhuis JD: Age and relative adiposity are specific negative determinants of the frequency and amplitude of growth hormone $(\mathrm{GH})$ secretory bursts and the half-life of endogenous $\mathrm{GH}$ in healthy men. J Clin Endocrinol Metab 1991; 73:1081-1088.
60 Toogood AA: Growth hormone (GH) status and body composition in normal ageing and in elderly adults with GH deficiency. Horm Res 2003;60:105-111.

61 Toogood AA: The somatopause: an indication for growth hormone therapy? Treat Endocrinol 2004;3:201-209.

62 Monson JP, Jonsson P: Aspects of growth hormone $(\mathrm{GH})$ replacement in elderly patients with GH deficiency: data from KIMS. Horm Res 2003;60(Suppl 1):112-120.

63 Li Voon Chong JS, Benbow S, Foy P, Wallymahmed ME, Wile D, MacFarlane IA: Elderly people with hypothalamic-pituitary disease and growth hormone deficiency: lipid profiles, body composition and quality of life compared with control subjects. Clin Endocrinol (Oxf) 2000;53:551-559.

64 Toogood AA, Nass RM, Pezzoli SS, O’Neill PA, Thorner MO, Shalet SM: Preservation of growth hormone pulsatility despite pituitary pathology, surgery, and irradiation. J Clin Endocrinol Metab 1997;82:2215-2221.

65 Toogood AA, Jones J, O’Neill PA, Thorner MO, Shalet SM: The diagnosis of severe growth hormone deficiency in elderly patients with hypothalamic-pituitary disease. Clin Endocrinol (Oxf) 1998;48:569-576.

66 Murray RD, Adams JE, Shalet SM: Adults with partial growth hormone deficiency have an adverse body composition. J Clin Endocrinol Metab 2004;89:1586-1591.
67 Tauber M, Jouret B, Cartault A, Lounis N, Gayrard M, Marcouyeux C, Pienkowski C, Oliver I, Moulin P, Otal P, Joffre F, Arnaud C, Rochiccioli P: Adolescents with partial growth hormone $(\mathrm{GH})$ deficiency develop alterations of body composition after $\mathrm{GH}$ discontinuation and require follow-up. J Clin Endocrinol Metab 2003;88:5101-5106.

68 Colao A, Cerbone G, Pivonello R, Aimaretti G, Loche S, Di Somma C, Faggiano A, Corneli G, Ghigo E, Lombardi G: The growth hormone $(\mathrm{GH})$ response to the arginine plus $\mathrm{GH}-$ releasing hormone test is correlated to the severity of lipid profile abnormalities in adult patients with GH deficiency. J Clin Endocrinol Metab 1999;84:1277-1282.

69 Colao A, Di Somma C, Pivonello R, Loche S, Aimaretti G, Cerbone G, Faggiano A, Corneli G, Ghigo E, Lombardi G: Bone loss is correlated to the severity of growth hormone deficiency in adult patients with hypopituitarism. J Clin Endocrinol Metab 1999;84: 1919-1924.

70 Murray RD, Adams JE, Shalet SM: A densitometric and morphometric analysis of the skeleton in adults with varying degrees of growth hormone deficiency. J Clin Endocrinol Metab 2006;91:432-438.

71 Murray RD, Shalet SM: Insulin sensitivity is impaired in adults with varying degrees of GH deficiency. Clin Endocrinol (Oxf) 2005; 62:182-188.

72 Carey DG, Jenkins AB, Campbell LV, Freund J, Chisholm DJ: Abdominal fat and insulin resistance in normal and overweight women: direct measurements reveal a strong relationship in subjects at both low and high risk of NIDDM. Diabetes 1996;45:633-638.

$\checkmark 73$ Murray RD: The phenotype of adults with partial growth hormone deficiency. Horm Res 2005;64(suppl 2):12-17. 